OPEN ACCESS

Edited by:

Chao Yan,

Xuzhou Medical University, China

Reviewed by:

Jianguo Wu,

Wuhan University, China

Jiang Zheng,

Xi'an Branch of Chinese Academy of

Sciences, China

${ }^{*}$ Correspondence:

Shide Lin

linshide6@hotmail.com

tThese authors have contributed equally to this work

Specialty section

This article was submitted to

Gastroenterology,

a section of the journal

Frontiers in Medicine

Received: 30 July 2020 Accepted: 21 December 2020 Published: 04 February 2021

Citation:

Chen H, Mu M, Liu Q, Hu H, Tian C,

Zhang G, Li Y, Yang F and Lin S (2021) Hepatocyte Endoplasmic Reticulum

Stress Inhibits Hepatitis B Virus Secretion and Delays Intracellular Hepatitis B Virus Clearance After

Entecavir Treatment.

Front. Med. 7:589040

doi: 10.3389/fmed.2020.589040

\section{Hepatocyte Endoplasmic Reticulum Stress Inhibits Hepatitis B Virus Secretion and Delays Intracellular Hepatitis B Virus Clearance After Entecavir Treatment}

Huan Chen ${ }^{\dagger}$, Maoyuan $\mathrm{Mu}^{\dagger}$, Qichuan Liu, Han Hu, Caiyun Tian, Guoyuan Zhang, Ying Li, Fangwan Yang and Shide Lin*

Department of Infectious Diseases, Affiliated Hospital of Zunyi Medical University, Zunyi, China

Background: The aim of this study was to explore the effects of endoplasmic reticulum (ER) stress on hepatitis B virus (HBV) replication and the antiviral effect of entecavir (ETV).

Methods: Thapsigargin (TG) and stearic acid (SA) were used to induce ER stress in HepG2.2.15 cells and HepAD38 cells that contained an integrated HBV genome, while ETV was used to inhibit HBV replication. The expression levels of glucose-regulated protein 78 (GRP78) and phosphorylated eukaryotic translation initiation factor 2 subunit alpha ( $p$-elF2 $\alpha$ ) were measured by western blotting. Intracellular HBV DNA was determined by qPCR; HBsAg by western blotting; HBV RNA by real-time RT-qPCR; HBsAg and HBeAg in supernatants by enzyme-linked immunosorbent assay (ELISA); and HBV DNA in supernatants by qPCR.

Results: TG and SA induced ER stress in HepG2.2.15 cells and HepAD38 cells from 12 to $48 \mathrm{~h}$ post treatment. However, 4-phenylbutyric acid (PBA) partly alleviated the TG-induced ER stress. Moreover, TG inhibited HBsAg, HBeAg, and HBV DNA secretion from 12 to $48 \mathrm{~h}$, while different concentrations of SA inhibited HBsAg and HBV DNA secretion at $48 \mathrm{~h}$. TG promoted intracellular HBV DNA and HBsAg accumulation and the transcription of the HBV 3.5-kb mRNA and S mRNA. PBA treatment restored the secretion of HBsAg and HBV DNA. Finally, ER stress accelerated extracellular HBV DNA clearance but delayed intracellular HBV DNA clearance after ETV treatment.

Conclusions: Hepatocyte ER stress promoted intracellular HBV DNA and HBsAg accumulation by inhibiting their secretion. Our study also suggested that hepatocyte ER stress delayed intracellular HBV DNA clearance after ETV treatment.

Keywords: endoplasmic reticulum stress, HepG2215, thapsigargin, stearic acid, HBsAg, HBV DNA

\section{INTRODUCTION}

Chronic hepatitis B virus (HBV) infection constitutes a global health concern. More than 240 million people are chronically infected with $\mathrm{HBV}$, which puts them at great risk of developing end-stage liver diseases such as liver failure, cirrhosis, and liver cancer (1). The progression of patients with chronic HBV infection depends on a complex interaction between the host and the virus (2). 
The HBV genome contains four partially overlapping open reading frames, named $\mathrm{C}, \mathrm{S}, \mathrm{P}$, and $\mathrm{X}$, from which 3.5-, 2.4-, 2.1-, and $0.7 \mathrm{~kb}$-long RNAs, respectively, are transcribed. Translation of the 2.4- and 0.7-kb fragments produces the large envelope protein and the HBx protein, respectively. The 2.1-kb mRNA yields both the middle and small envelope proteins. The 3.5$\mathrm{kb}$ long RNA, also called pregenomic RNA, is the only HBV transcript required for genome replication $(1,3)$.

The endoplasmic reticulum (ER) is an important cellular organelle and plays a major role in protein synthesis, folding, modification, and transport, as well as in lipid synthesis and the maintenance of calcium homeostasis. When ER homeostasis is disturbed under physical or pathological stimuli, such as the disruption of calcium homeostasis, the accumulation of unfolded or misfolded proteins, glucose starvation, and hypoxia, the unfolded protein response (UPR) is activated (4). ER stress can initiate the UPR via the binding of glucose-regulated protein 78 (GRP78) to unfolded or misfolded proteins and by activating three different sensors: protein kinase R-like endoplasmic reticulum kinase (PERK), inositol-requiring enzyme 1 (IRE1), and activating transcription factor 6 (ATF6).

ER stress is a common pathological phenomenon in patients with liver disease, including viral hepatitis, fatty liver disease, alcoholic liver disease, drug-induced hepatitis, and ischemic liver damage, among others $(5,6)$. Viruses, fatty acids, alcohol, and drugs can all induce ER stress in hepatocytes, which can damage these cells and lead to metabolic disorders.

$\mathrm{HBV}$ and hepatocytes have a complex and close interaction. The activation of HBV enhancers largely depends on cellular factors expressed in hepatocytes $(7,8)$. Transcription factors in hepatocytes such as CCAAT/enhancer-binding protein (C/EBP), cyclic-adenosine monophosphate-responsive element-binding protein (CREB), and several other nuclear factors have been found to play an important role in HBV enhancer activation (8, 9). In the HBV life cycle, secretory proteins, such as HBsAg and HBeAg, are folded and assembled in the ER of hepatocytes (10). However, how hepatocyte ER stress affects HBV replication, and the antiviral effect of nucleos(t)ide analogs, remains unknown. In this study, we employed thapsigargin (TG) and stearic acid (SA) as ER stress inducers in HBV-transfected HepG2.2.15 cells and HepAD38 cells to investigate the impact of ER stress on HBV replication and the antiviral efficacy of entecavir (ETV).

\section{MATERIALS AND METHODS}

\section{Reagents}

RPMI 1640 was obtained from Thermo-Fisher Biochemical Products Co., Ltd (Beijing, China). TG, SA, and 4-phenylbutyric acid (PBA) were purchased from Sigma (St. Louis, MO, USA). Antibodies against GRP78, HBsAg, and beta-actin were purchased from Santa Cruz Biotechnology (Santa Cruz, CA, USA). The anti-phosphorylated eukaryotic translation initiation factor 2 alpha (p-eIF2 $\alpha$ ) antibody was purchased from Cell Signaling Technology (BioConcept, Allschwil, Switzerland). ETV was purchased from Solarbio Science \& Technology Co., Ltd
(Beijing, China). All other chemicals and reagents were obtained from Sigma (St. Louis, MO, USA).

\section{Cell Culture}

HepG2.2.15 cells and HepAD38 cells with a stably integrated HBV genome were obtained from the cell bank of the Type Culture Collection of the Chinese Academy of Sciences (Shanghai, China). HepG2.2.15 cells and HepAD38 cells were cultured to $80-100 \%$ confluence. To investigate the effects of TG and SA on ER stress, HepG2.2.15 and HepAD38 cells were treated with TG $(1 \mu \mathrm{M})$ for $12,24,36$, and $48 \mathrm{~h}$ or SA $(50,100$, or $200 \mu \mathrm{M})$ for $48 \mathrm{~h}$. Similarly, PBA was used to alleviate ER stress and ETV to inhibit HBV replication. Briefly, HepG2.2.15 cells were pretreated with PBA $(1 \mathrm{mM})$ for $2 \mathrm{~h}$ and then incubated with TG for $96 \mathrm{~h}$, whereas ETV $(10 \mu \mathrm{M})$ and TG $(1 \mu \mathrm{M})$ were simultaneously administered for the same length of time. SA $(0.017 \mathrm{~g})$ was dissolved in $3 \mathrm{ml}$ of $0.1 \mathrm{mM} \mathrm{NaOH}$ in a water bath at $100^{\circ} \mathrm{C}$. Stock solutions were prepared by adding $3 \mathrm{ml}$ of $40 \%$ fatty acid-free bovine serum albumin to each tube and incubating for $30 \mathrm{~min}$ at $55^{\circ} \mathrm{C}$. The final SA concentration was $10 \mathrm{mM}$. All control conditions included the corresponding vehicles at the appropriate concentrations.

\section{Flow Cytometry}

Apoptosis was determined using an Annexin V-fluorescein isothiocyanate (FITC)/propidium iodide (PI) apoptosis detection kit following the manufacturer's instructions. Briefly, $2 \times$ $10^{6}$ cells were harvested and washed twice with precooled PBS and resuspended in $500 \mu \mathrm{l}$ of binding buffer. Then, $5 \mu \mathrm{l}$ of Annexin V-FITC and $5 \mu \mathrm{l}$ of PI was added to each sample followed by incubation at room temperature in the dark for $10 \mathrm{~min}$. Analysis was performed by flow cytometry (Beckman Coulter Gallios, USA) according to the manufacturer's specifications.

\section{Western Blotting}

Cell lysates containing $40 \mu \mathrm{g}$ of protein were resolved by sodium dodecyl sulfate-polyacrylamide gel electrophoresis (SDS-PAGE) using a 7-12.5\% polyacrylamide gradient gel, and the fractioned proteins were subsequently transferred to polyvinylidene fluoride membranes (Millipore, Billerica, MA, USA). After being blocked with Tris-buffered saline containing $5 \%$ dry milk and $0.1 \%$ Tween 20 for $1 \mathrm{~h}$, the membranes were blotted with the corresponding antibodies. The following primary antibodies were used: rabbit antihuman GRP78 (sc-376768, 1:10,000), anti-p-eIF-2 $\alpha$ (3398, $1: 10,000)$, mouse anti-human $\beta$-actin (sc-58673, 1:10,000), and anti-HBsAg (sc-53300, 1:1,000). The secondary antibodies were horseradish peroxidase-conjugated goat anti-rabbit IgG and horseradish peroxidase-conjugated goat anti-mouse IgG. The membranes were developed using a chemiluminescence detection system and then exposed to Kodak BioMax Light Film (Rochester, NY, USA). The band intensity for each protein was measured densitometrically and normalized to the level of $\beta$-actin. 


\section{Quantification of $\mathrm{HBsAg}$ and $\mathrm{HBeAg}$}

HepG2.2.15 and HepAD38 cells were cultured at a density of $1 \times 10^{4}$ cells per well in RPMI 1640 medium. After drug treatment, the levels of $\mathrm{HBsAg}$ and $\mathrm{HBeAg}$ in the supernatants were measured using an enzyme-linked immunosorbent assay (ELISA) (Kehua Bio-engineering Corp.) according to the manufacturer's recommendations.

\section{DNA and RNA Isolation, Reverse Transcription, and Real-Time Polymerase Chain Reaction}

Total DNA was extracted using a QIAamp DNA Mini Kit (Qiagen). Total RNA was extracted from HepG2.2.15 cells using a TaKaRa MiniBEST Universal RNA Extraction Kit (9767, Takara). The HBV DNA content was quantified by real-time qPCR using SYBR Green I. The primers used to amplify the HBV DNA were as follows: $5^{\prime}$-GTTGCCCGTTTGTCCTCTAATTC-3' and 5'-GGAGGGATACATAGAGGTTCCTT-3'. Quantitative PCR was performed at $95^{\circ} \mathrm{C}$ for $30 \mathrm{~s}, 40$ cycles of $95^{\circ} \mathrm{C}$ for
$5 \mathrm{~s}$, and $60^{\circ} \mathrm{C}$ for $34 \mathrm{~s}$, followed by melting curve analysis, according to the instrument documentation. The RNA samples were first reverse transcribed into cDNA using the PrimeScript RT Reagent Kit (DRR037A, Takara). The products were then subjected to $\mathrm{qPCR}$ using the following primers: HBV-S mRNA, 5'-CTAGGACCCCTGCTCGTG$3^{\prime}$ and $5^{\prime}$-GATGAGGCATAGCAGCAG-3'; HBV $3.5-\mathrm{kb}$ mRNA, 5'-CTCAATCTCGGGAATCTCAATGT-3' and $5^{\prime}-$ TGGATAAAACCTAGCAGGCATAAT- $3^{\prime}$; and GADPH mRNA, 5'-CGACCACTTTGTCAAGCTCA-3' and 5'ACAGCCTGGATAGCAACG- $3^{\prime}$. The relative HBV DNA and mRNA levels were determined using the comparative $\left(2^{-\Delta \Delta C T}\right)$ method, as previously described (11).

\section{Statistical Analysis}

The results were expressed as means \pm standard deviation for " $n$ " independent observations. One-way ANOVA was used to determine the statistical differences between the mean values for the groups. The level of significance was set at $P<0.05$.

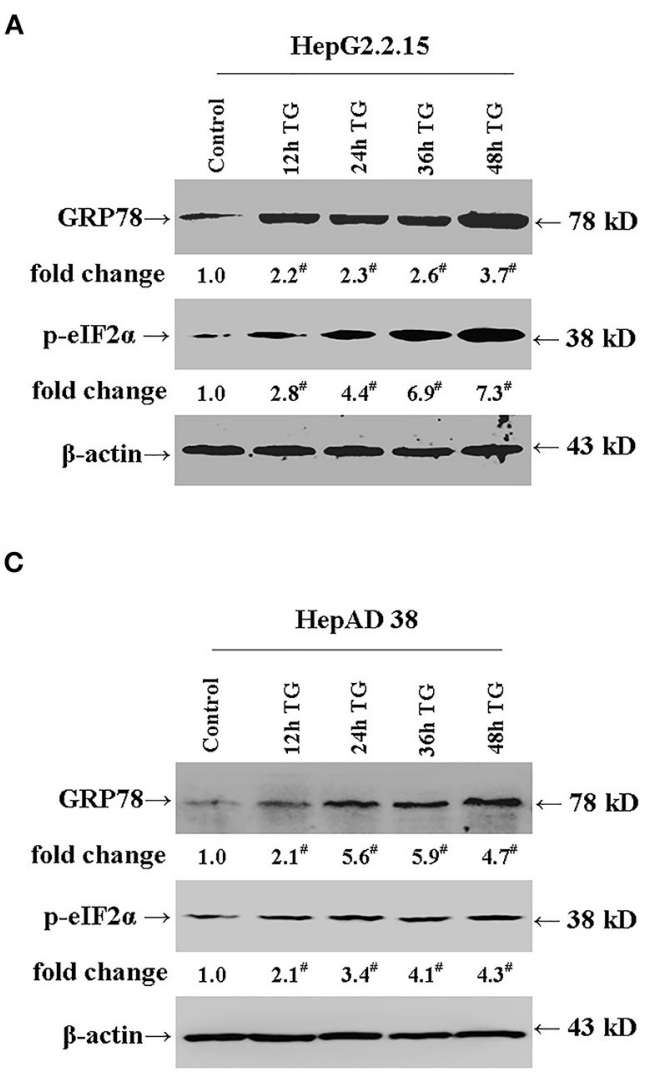

B

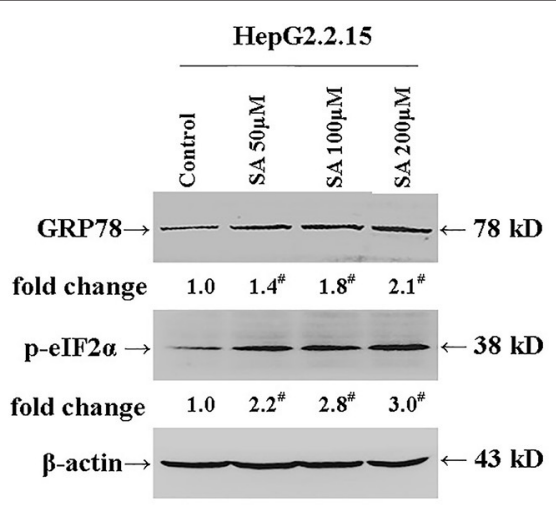

D

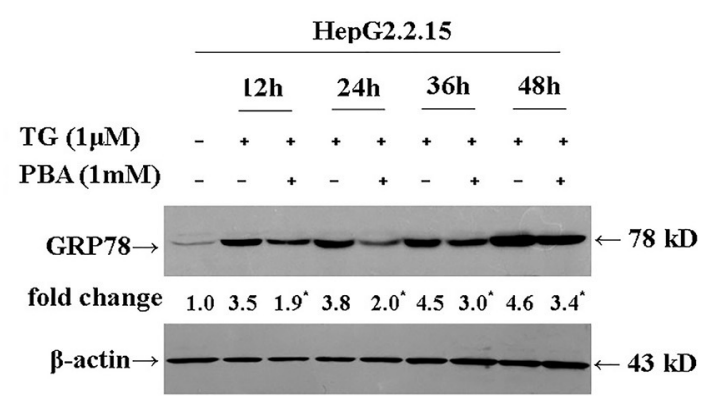

FIGURE 1 | TG and SA induced ER stress in HepG2.2.15 and HepAD38 cells, which was alleviated by PBA treatment. HepG2.2.15 and HepAD38 cells were treated with $1 \mu \mathrm{M}$ of TG for $12,24,36$, and $48 \mathrm{~h}$ or 50,100 , and $200 \mu \mathrm{M}$ of SA for $48 \mathrm{~h}$. The expression of GRP78 and p-elF2 $\alpha$ was assessed by western blotting. Representative blots from three independent experiments are shown. The results of the densitometric analysis are presented as fold-changes compared with control or TG. (A) GRP78 and p-elF2 $\alpha$ expression in HepG2.2.15 cells after TG treatment. \#P<0.05 vs. control. (B) GRP78 and p-elF2 $\alpha$ expression in HepG2.2.15 cells following SA treatment. $\# P<0.05$ vs. control. (C) GRP78 and p-elF2 $\alpha$ expression in HepAD38 cells after TG treatment. \# $P<0.05$ vs. control. (D) GRP78 expression in HepG2.2.15 cells after TG or PBA $(1 \mathrm{mM})+$ TG treatment. ${ }^{*} P<0.05$ vs. the TG group. ER, endoplasmic reticulum; GRP78, glucose-regulated protein 78; PBA, 4-phenylbutyric acid; p-elF2 $\alpha$, phospho-eukaryotic translation initiation factor 2 alpha; SA, stearic acid; TG, thapsigargin. 


\section{RESULTS}

\section{Thapsigargin and Stearic Acid Treatment Induced Endoplasmic Reticulum Stress in HepG2.2.15 and HepAD38 Cells, Which Was Alleviated by Exposure to 4-Phenylbutyric Acid}

We first investigated whether TG and SA induced ER stress in HepG2.2.15 and HepAD38 cells. As shown in Figures 1A,B, TG significantly induced GRP78 and p-eIF2 $\alpha$ expression from 12 to $48 \mathrm{~h}$ post treatment at the $1-\mu \mathrm{M}$ concentration in HepG2.2.15 cells. Similarly, SA markedly induced GRP78 and p-eIF $2 \alpha$ expression at $48 \mathrm{~h}$ at the concentrations of 50, 100, and $200 \mu \mathrm{M}$ in HepG2.2.15 cells. At $100 \mu \mathrm{M}$, SA significantly induced GRP78 expression from 24 to $72 \mathrm{~h}$, as did TG at $24 \mathrm{~h}$ at the concentrations of $0.5,1$, and $2 \mu \mathrm{M}$ in HepG2.2.15 cells (Supplementary Figures 1,2). Furthermore, $1 \mu \mathrm{M}$ of TG significantly induced GRP78 and p-eIF2 $\alpha$ expression from 12 to $48 \mathrm{~h}$ post treatment in HepAD38 cells (Figure 1C). Our results demonstrated that both TG and SA could induce ER stress and activate the UPR in HepG2.2.15 cells and HepAD38 cells.

Next, we investigated whether PBA could alleviate the ER stress induced by TG (Figure 1D). We found that at the $1-\mathrm{mM}$ concentration, PBA could significantly inhibit the TG-mediated induction of GRP78 expression, demonstrating that PBA could alleviate TG-induced ER stress.

We next evaluated the effect of TG and SA on the apoptosis and viability of HepG2.2.15 cells. At the concentration of $1 \mu \mathrm{M}$, TG treatment did not lead to a marked increase in the rate of apoptosis from 12 to $48 \mathrm{~h}$ post treatment, and a similar effect was observed for SA treatment $(50$ and $100 \mu \mathrm{M})$ at $48 \mathrm{~h}$ (Supplementary Figure 3).

\section{Thapsigargin and Stearic Acid Inhibited the Secretion of HBsAg, $\mathrm{HBeAg}$, and Hepatitis B Virus DNA}

We subsequently explored the effect of TG $(1 \mu \mathrm{M})$ and SA $(50,100$, and $200 \mu \mathrm{M})$ on the secretion of HBsAg, $\mathrm{HBeAg}$, and HBV DNA in HepG2.2.15 supernatants. As shown in Figures 2, 3, exposure to TG significantly inhibited the secretion of HBsAg, HBeAg, and HBV DNA from 12 to $48 \mathrm{~h}$ post treatment. Similarly, treatment with 50,100 , and $200 \mu \mathrm{M}$ of SA also greatly suppressed the secretion of HBsAg and HBV DNA at $48 \mathrm{~h}$. We further found that TG significantly inhibited the secretion of HBsAg from 12 to $48 \mathrm{~h}$ post treatment in HepAD38 cells (Figure 2C). Western blotting results confirmed that TG significantly inhibited the secretion of HBsAg from 12 to $48 \mathrm{~h}$. However, SA treatment did not significantly affect the secretion of $\mathrm{HBeAg}$, at the concentration of either 50 or $100 \mu \mathrm{M}$ (Figure 3). At $100 \mu \mathrm{M}, \mathrm{SA}$ also significantly inhibited the
A

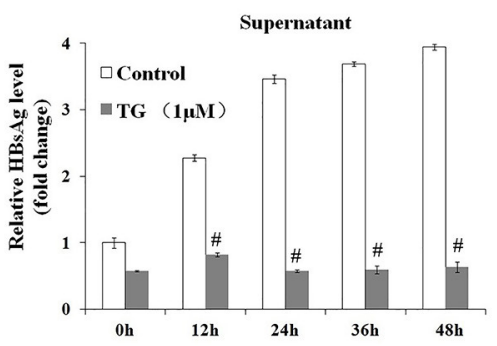

D

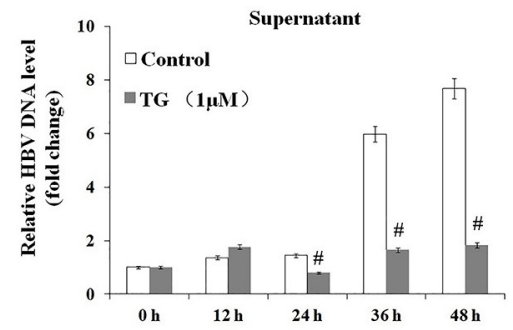

B

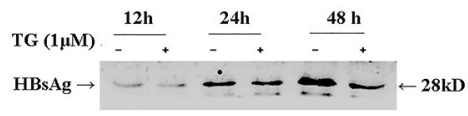

$\mathbf{E}$

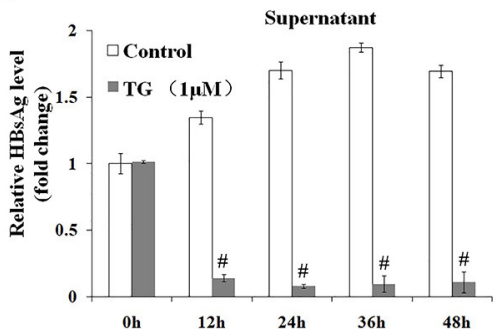

C

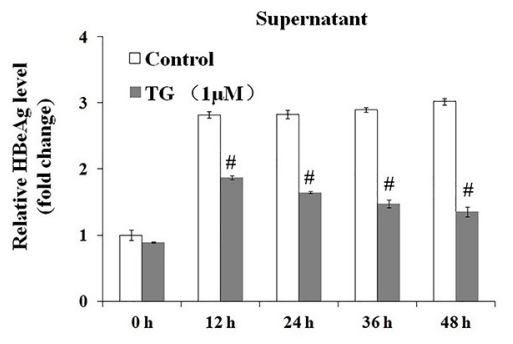

FIGURE 2 | Thapsigargin (TG) inhibited HBsAg, HBeAg, and hepatitis B virus (HBV) DNA secretion in HepG2.2.15 cells and HepAD38 cells. HepG2.2.15 cells and HepAD38 cells were treated with $1 \mu \mathrm{M}$ of TG for 12, 24, 36, and $48 \mathrm{~h}$. The supernatant levels of HBsAg and HBeAg were determined by ELISA or western blotting, while those of HBV DNA were determined by GPCR. (A) HBsAg levels as determined by ELISA in HepG2.2.15 cells. (B) HBsAg levels as determined by western blotting in HepG2.2.15 cells. (C) HBeAg levels as determined by ELISA in HepG2.2.15 cells. (D) HBV DNA levels as determined by qPCR in HepG2.2.15 cells. (E) HBsAg levels as determined by western blotting in HepAD38 cells. The results are presented as fold-changes compared with the control. Histograms represent the means $\pm S D$ of three independent experiments. $\# P<0.05$ vs. the control. 

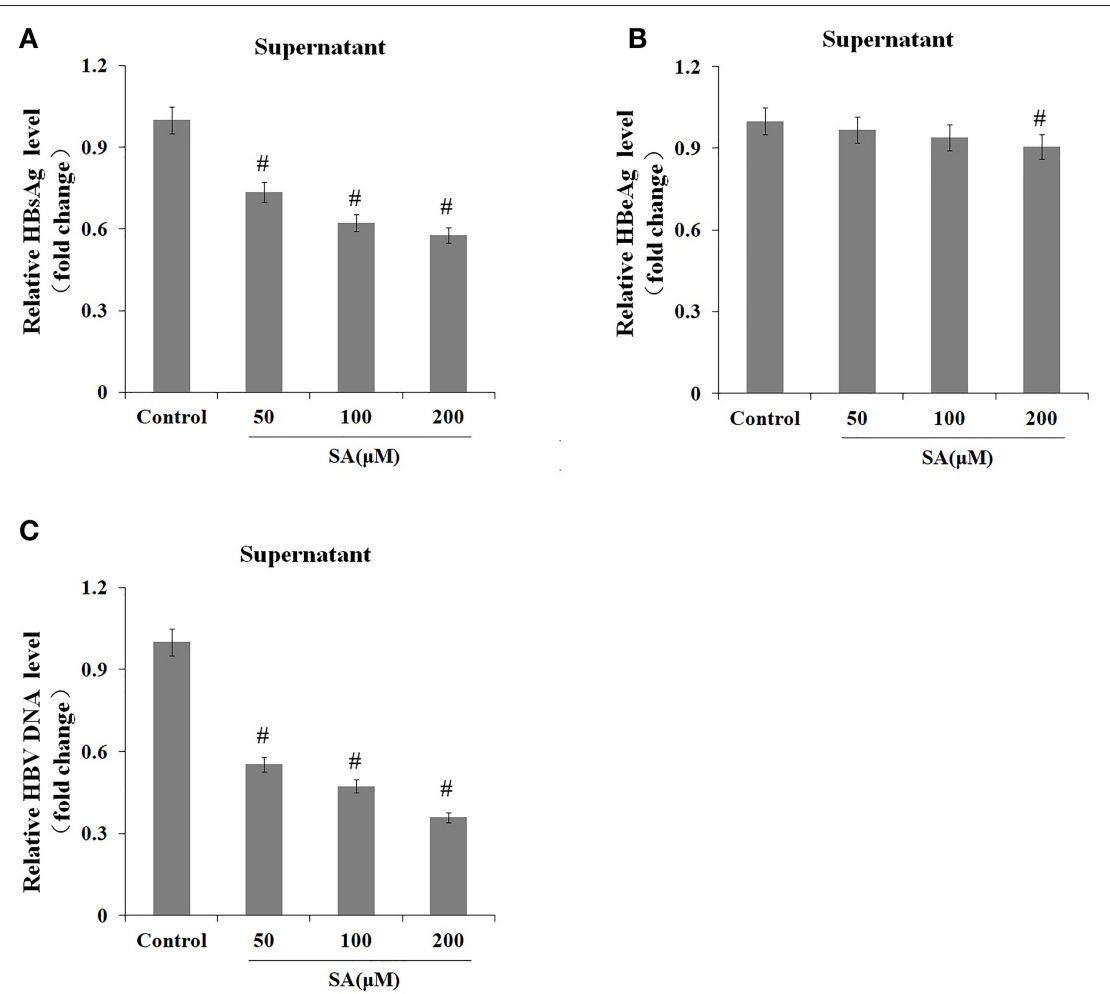

FIGURE 3 | Stearic acid (SA) inhibited the secretion of HBsAg and hepatitis B virus (HBV) DNA in HepG2.2.15 cells. HepG2.2.15 cells were treated with 50, 100, and $200 \mu \mathrm{M}$ of SA for $48 \mathrm{~h}$. The supernatant levels of HBsAg and HBeAg were determined by ELISA, while those of HBV DNA were determined by qPCR. (A) HBsAg levels as determined by ELISA. (B) HBeAg levels as determined by ELISA. (C) HBV DNA levels as determined by qPCR. The results are presented as fold-changes compared with the control. Histograms represent the means $\pm S D$ of three independent experiments. $\# P<0.05$ vs. the control.

secretion of HBsAg and HBV DNA from 24 to $72 \mathrm{~h}$, as did TG at $24 \mathrm{~h}$ at the concentrations of $0.5,1$, and $2 \mu \mathrm{M}$ in HepG2.2.15 cells (Supplementary Figures 4-7).

\section{The Effects of Thapsigargin on the Transcription of Hepatitis B Virus DNA and Intracellular HBsAg and Hepatitis B Virus DNA Levels}

We further explored the effects of TG on the expression levels of the 3.5-kb mRNA and S mRNA as well as on the intracellular levels of HBsAg and HBV DNA. As shown in Figure 4, TG significantly upregulated the expression of the $\mathrm{HBV} 3.5-\mathrm{kb}$ mRNA fragment and S mRNA and increased the intracellular levels of HBsAg and HBV DNA. Western blotting confirmed that the intracellular level of HBsAg was significantly increased by TG from 12 to $48 \mathrm{~h}$ post treatment.

\section{Thapsigargin Inhibited the Secretion of} HBsAg and Hepatitis B Virus DNA via the Induction of Endoplasmic Reticulum Stress We then investigated whether the inhibitory effects of TG on HBsAg and HBV DNA secretion were exerted through the induction of ER stress. As shown in Figure 5, the secretion of
HBsAg and HBV DNA was significantly restored by PBA at $36 \mathrm{~h}$ post treatment. Similarly, $\mathrm{HBeAg}$ levels in the supernatant were also partially restored. These results strongly suggested that TG inhibited HBsAg, $\mathrm{HBeAg}$, and HBV DNA secretion through the induction of ER stress.

\section{Thapsigargin Delayed Intracellular Hepatitis B Virus Clearance After Entecavir Treatment}

Finally, we assessed whether the TG-induced ER stress impaired the antiviral effect of ETV. After $96 \mathrm{~h}$ of ETV treatment, HBV replication was significantly inhibited (Figure 6). TG treatment significantly delayed the intracellular clearance of HBV DNA, HBsAg, and HBV RNA; in contrast, TG treatment significantly accelerated the extracellular clearance of HBV DNA, HBsAg, and $\mathrm{HBeAg}$.

\section{DISCUSSION}

HBV assembly and HBsAg synthesis and secretion are highly dependent on ER function $(10,12)$. Each of the HBV envelope proteins is cotranslationally inserted into the ER membrane. The middle and small proteins have single transmembrane domains, 

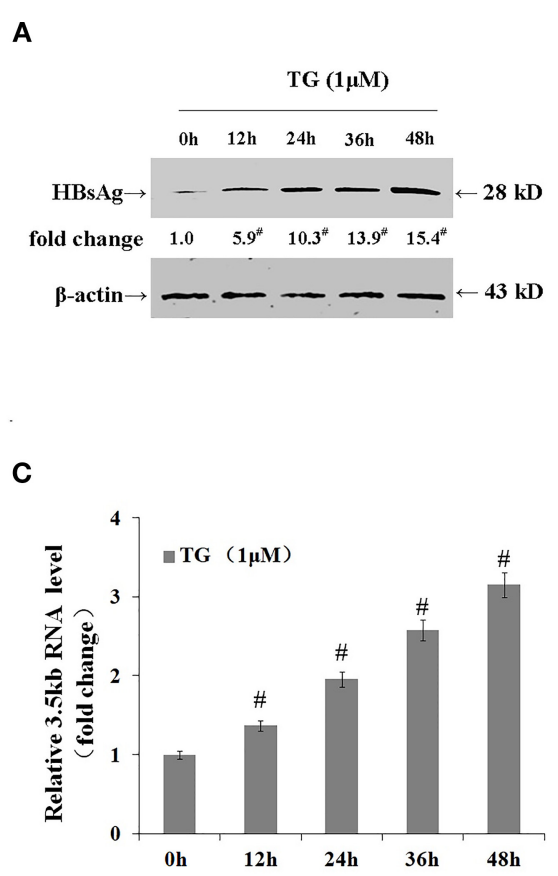

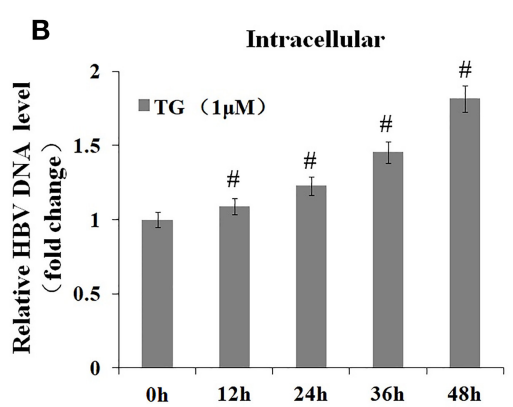

D

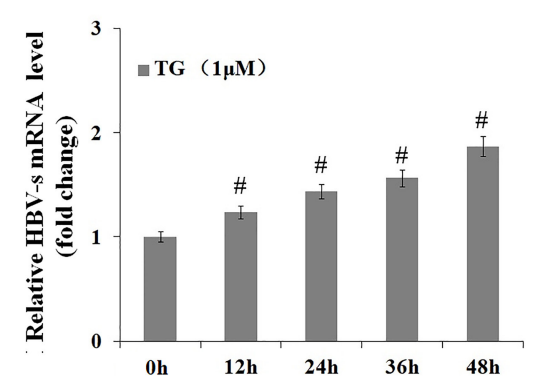

FIGURE 4 | Thapsigargin (TG) promoted hepatitis B virus (HBV) DNA transcription and the accumulation of HBV DNA and HBsAg in HepG2.2.15 cells. HepG2.2.15 cells were treated with $1 \mu \mathrm{M}$ of TG for $12,24,36$, and $48 \mathrm{~h}$. Intracellular HBsAg, HBV DNA, and HBV RNA levels were determined by western blotting, qPCR, and real-time RT-qPCR, respectively. The results are presented as fold-changes compared with the control. Histograms represent the means $\pm S D$ of three independent experiments. $\# P<0.05$ vs. control. (A) HBsAg levels as determined by western blotting. Representative blots from three independent experiments are shown. (B) HBV DNA levels as determined by qPCR. (C) HBV 3.5-kb mRNA levels as determined by RT-qPCR. (D) HBV S mRNA levels as determined by RT-qPCR.

whereas the large protein has a unique dual transmembrane conformation topology in the ER. The large protein is modified by myristoylation, but this is dispensable for virion formation (13-15). Host chaperones, such as heat shock protein 70 (HSP70) and GRP78/Bip, play an important role in the correct folding of envelope proteins and the maintenance of the dual topology of the large protein in the ER $(16,17)$. The synthesis of HBeAg is also closely associated with the ER $(18,19)$. As HBV replication and antigen secretion in vivo are both dependent on a complex interaction between the host and the virus, such as the activation of immune cells and the regulation of cytokine levels, it is difficult to identify the direct effect of ER stress on HBV replication in vivo. In this study, we used TG and SA to induce ER stress in HepG2.2.15 cells containing an integrated HBV genome and HepAD38 cells, and the results obtained mostly reflect the direct effect of ER stress on HBV replication.

In this study, we found for the first time that hepatocyte ER stress greatly suppressed HBsAg and HBV DNA secretion and increased the intracellular levels of HBsAg and HBV DNA. How ER stress affects HBV replication remains unknown. Several studies have reported that the accumulation of mutated HBsAg in hepatocytes results in ER stress and the activation of the UPR both in vitro and in vivo (20-22). However, the results regarding the effect of hepatocyte ER stress on HBV replication have been contradictory, and several different mechanisms have been suggested to be involved. $\mathrm{Xu}$ et al. reported that hepatocyte ER stress induced by the retention of the large protein of the $\mathrm{HBV}$ can activate the $\mathrm{S}$ promoter; increase the synthesis of the middle and small proteins to restore the proportions of the large, middle, and small proteins in cells; and maintain the assembly of HBV particles (23). Additionally, the authors also found that the transcriptional activation of the $S$ promoter was cell type-restricted and was mediated through the IRE1 $\alpha / \mathrm{X}$-box binding protein 1 (XBP1) pathway. A different study demonstrated that, in HBV-infected hepatoma cells, the ER stress-associated degradation pathway was activated, leading to the degradation of the HBV envelope protein and the consequent inhibition of HBV replication (24). Cisplatin-induced ER stress in hepatocytes has also been found to evoke HBV reactivation via the peroxisome proliferatoractivated receptor gamma coactivator 1 alpha (PPARGC1A) signaling pathway (25). GRP78 is a master ER stress regulator, the expression of which is significantly upregulated during ER stress. Several studies have demonstrated that GRP78 expression can inhibit HBV DNA replication (26-28). We do not know the reasons for these differing results. In this study, we used TG and SA to induce ER stress, and we found that both inhibited HBV DNA and HBsAg secretion, while TG also promoted intracellular HBV DNA and HBsAg accumulation. PBA is a lowmolecular-weight chemical chaperone that effectively prevents misfolded protein aggregation and alleviates ER stress. After PBA administration, HBV DNA and HBsAg secretion were partly 

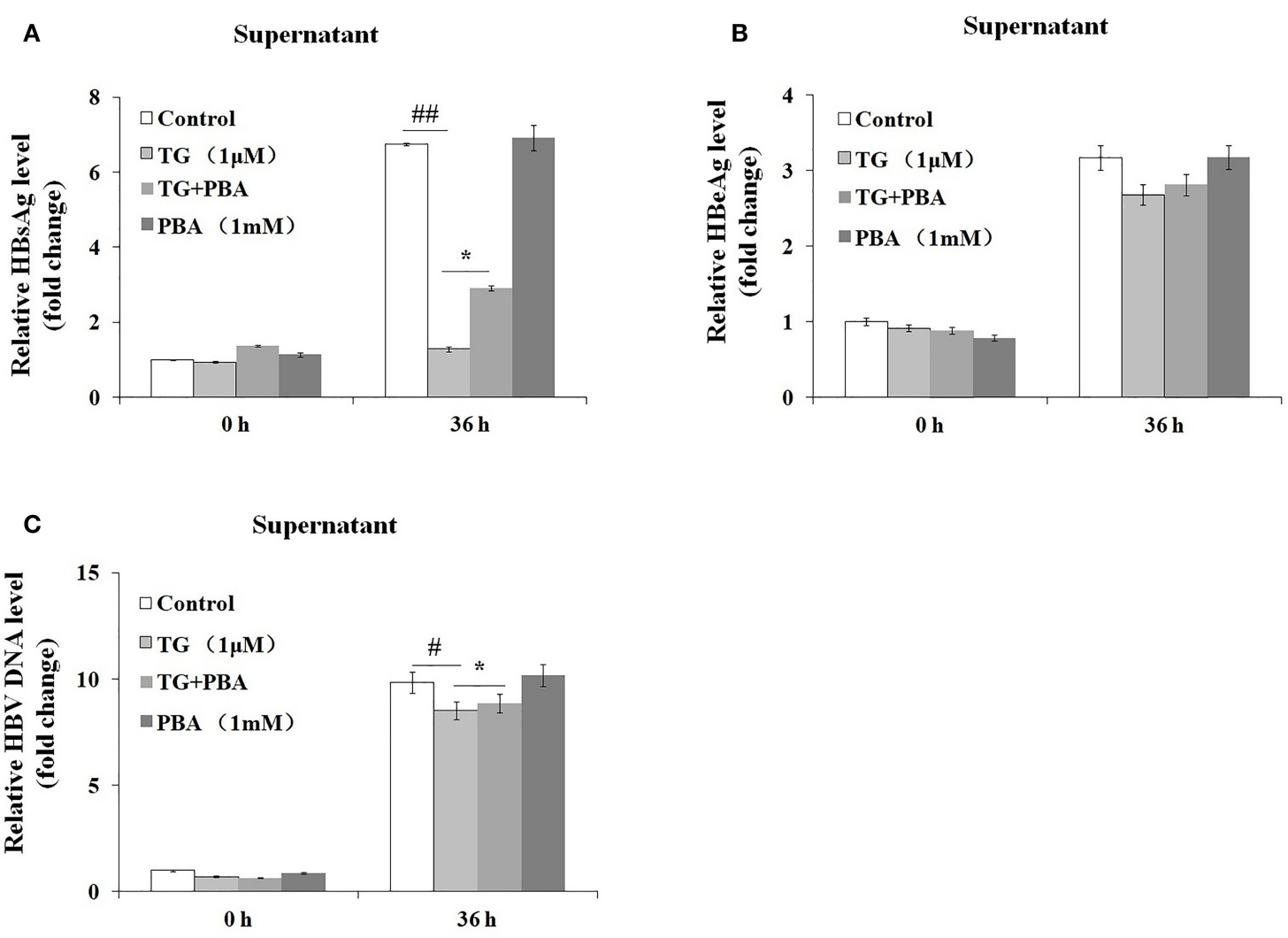

FIGURE 5 | 4-Phenylbutyric acid (PBA) pretreatment restored the secretion of hepatitis B virus (HBV) DNA, HBsAg, and HBeAg in HepG2.2.15 cells. HepG2.2.15 cells were treated with $1 \mu \mathrm{M}$ of thapsigargin (TG) with or without $1 \mathrm{mM}$ of PBA for $12,24,36$, and $48 \mathrm{~h}$. The supernatant levels of HBsAg and HBeAg were determined by ELISA, while those of HBV DNA were determined by qPCR. The results are presented as fold-changes compared with the control. Histograms represent the means $\pm S D$ of three independent experiments. ${ }^{\#} P<0.05$ vs. the control $\# \# P<0.01, \# P<0.05$ vs. the control; ${ }^{*} P<0.05$. (A) HBsAg and (B) HBeAg levels as determined by ELISA. (C) HBV DNA levels as determined by qPCR.

restored. These results demonstrated that the inhibitory effects of TG and SA on HBV DNA and HBsAg secretion were at least partly dependent on the induction of ER stress.

The ER is the largest $\mathrm{Ca}^{2+}$ store in hepatocytes. $\mathrm{Ca}^{2+}$ release from the ER is a common mechanism underlying the occurrence and progression of ER stress following both physical and pathological cues. TG induces ER stress by irreversibly inhibiting sarcoplasmic/ER $\mathrm{Ca}^{2+}$-ATPase, which blocks the reabsorption of calcium from the cytosol to the ER and leads to an increase in the cytosolic $\mathrm{Ca}^{2+}$ concentration (29). Cytosolic $\mathrm{Ca}^{2+}$ can stimulate the Pyk2/Src kinase signal transduction pathway, thereby activating HBV reverse transcription and DNA replication (30). However, one study reported that HBV DNA replication was inhibited following the blocking of the ER $\mathrm{Ca}^{2+}$-ATPase (12). How SA, a saturated fatty acid, induces ER stress remains unclear. High saturated fatty acid concentrations have been found to impair ER structure and function (31). In our study, both TG and SA inhibited the secretion of HBV DNA and HBsAg. However, these effects were partially attenuated following PBA-mediated alleviation of ER stress. These results further supported that the inhibition of HBV DNA and HBsAg secretion by TG and SA was partly mediated via the induction of ER stress. However, whether TG promoted the transcription of both the HBV 3.5-kb mRNA fragment and $\mathrm{S}$ mRNA via an increase in the cytosolic $\mathrm{Ca}^{2+}$ concentration warrants further study.

Another major finding of this study was that, although ETV displayed high antiviral efficacy in the presence of TG, treatment with TG accelerated extracellular HBV DNA, HBsAg, and $\mathrm{HBeAg}$ clearance but delayed the clearance of intracellular HBV DNA, HBsAg, and HBV mRNA. These results suggested that hepatocyte ER stress delayed intracellular HBV clearance. The intracellular HBV DNA and HBsAg accumulation induced by TG exposure may partly explain this result. However, the mechanism underlying the impaired HBsAg and HBV DNA secretion and the enhanced transcription of the HBV 3.5-kb mRNA and S mRNA under ER stress needs further clarification. Additionally, given that ER stress is a common pathological phenomenon in patients with liver disease, the clinical significance of the delayed intracellular HBV clearance under ER stress after ETV treatment should also be explored.

In conclusion, this study is the first to report that hepatocyte ER stress promotes intracellular HBV DNA and HBsAg accumulation by inhibiting HBV DNA and HBsAg secretion. Our 


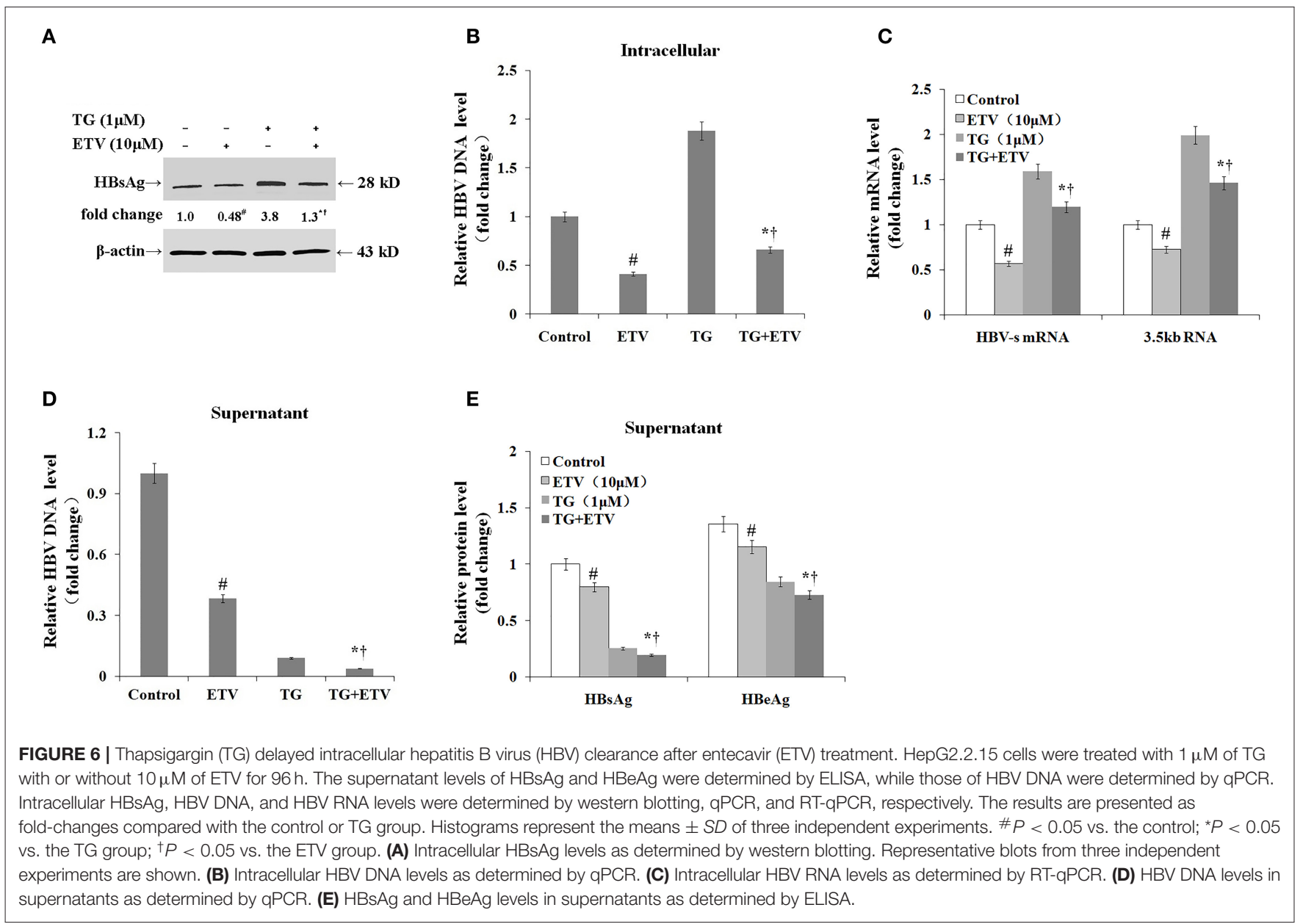

study also suggested that hepatocyte ER stress delays intracellular HBV DNA clearance after ETV treatment.

\section{DATA AVAILABILITY STATEMENT}

The original contributions presented in the study are included in the article/Supplementary Materials, further inquiries can be directed to the corresponding author/s.

\section{AUTHOR CONTRIBUTIONS}

SL designed the experiments and wrote the manuscript. HC, MM, QL, HH, and GZ performed the experiments. YL and FY revised the manuscript and analyzed the data. All authors read and approved the final manuscript.

\section{REFERENCES}

1. Tong S, Revill P. Overview of hepatitis B viral replication and genetic variability. $J$ Hepatol. (2016) 64(1Suppl.):S416. doi: 10.1016/j.jhep.2016.01.027

\section{FUNDING}

This work was supported by funding from the Chinese National Natural Science Foundation Project (81460124 and 81860114). The funders had no role in the study design and analysis, decision to publish, or preparation of the manuscript. No additional external funding was received for this study.

\section{SUPPLEMENTARY MATERIAL}

The Supplementary Material for this article can be found online at: https://www.frontiersin.org/articles/10.3389/fmed. 2020.589040/full\#supplementary-material

2. European Association for the Study of the Liver. Clinical Practice Guidelines on the management of hepatitis B virus infection. J Hepatol. (2017) 67:37098. doi: 10.1016/j.jhep.2017.03.021

3. Seeger C, Mason WS. Molecular biology of hepatitis B virus infection. Virology. (2015) 479-80:672-86. doi: 10.1016/j.virol.2015.02.031 
4. Oakes SA, Papa FR. The role of endoplasmic reticulum stress in human pathology. Annu Rev Pathol. (2015) 10:17394. doi: 10.1146/annurev-pathol-012513-104649

5. Wu FL, Liu WY, Van Poucke S, Braddock M, Jin WM, Xiao J, et al. Targeting endoplasmic reticulum stress in liver disease. Expert Rev Gastroenterol Hepatol. (2016) 10:1041-52. doi: 10.1080/17474124.2016.1179575

6. Kim SY, Kyaw YY, Cheong J. Functional interaction of endoplasmic reticulum stress and hepatitis B virus in the pathogenesis of liver diseases. World J Gastroenterol. (2017) 23:7657-65. doi: 10.3748/wjg.v23.i43.7657

7. Ezzikouri S, Ozawa M, Kohara M, Elmdaghri N, Benjelloun S, TsukiyamaKohara K. Recent insights into hepatitis B virus-host interactions. J Med Virol. (2014) 86:925-32. doi: 10.1002/jmv.23916

8. Kong F, You H, Kong D, Zheng K, Tang R. The interaction of hepatitis B virus with the ubiquitin proteasome system in viral replication and associated pathogenesis. Virol J. (2019) 16:73. doi: 10.1186/s12985-019-1183-z

9. Tang H, McLachlan A. Transcriptional regulation of hepatitis B virus by nuclear hormone receptors is a critical determinant of viral tropism. Proc Natl Acad Sci U S A. (2001) 98:1841-6. doi: 10.1073/pnas.98.4.1841

10. Patzer EJ, Nakamura GR, Simonsen CC, Levinson AD, Brands R. Intracellular assembly and packaging of hepatitis B surface antigen particles occur in the endoplasmic reticulum. J Virol. (1986) 58:88492. doi: 10.1128/JVI.58.3.884-892.1986

11. Wu L, Wang W, Zhang X, Zhao X, Yu G. Anti-HBV activity and mechanism of marine-derived polyguluronate sulfate (PGS) in vitro. Carbohydr Polym. (2016) 143:139-48. doi: 10.1016/j.carbpol.2016.01.065

12. Xia $\mathrm{W}$, Shen $\mathrm{Y}$, Xie $\mathrm{H}$, Zheng $\mathrm{S}$. Involvement of endoplasmic reticulum in hepatitis B virus replication. Virus Res. (2006) 121:116-21. doi: 10.1016/j.virusres.2006.01.020

13. Bruss V, Ganem D. The role of envelope proteins in hepatitis B virus assembly. Proc Natl Acad Sci U S A. (1991) 88:1059-63. doi: 10.1073/pnas.88.3.1059

14. Dorobantu C, Macovei A, Lazar C, Dwek RA, Zitzmann N, BranzaNichita N. Cholesterol depletion of hepatoma cells impairs hepatitis B Virus envelopment by altering the topology of the large envelope protein. $J$ Virol. (2011) 85:13373-83. doi: 10.1128/JVI.05423-11

15. Lambert C, Prange R. Posttranslational N-glycosylation of the hepatitis B virus large envelope protein. Virol J. (2007) 4:45. doi: 10.1186/1743-422X-4-45

16. Cho D-Y, Yang G-H, Ryu CJ, Hong HJ. Molecular chaperone GRP78/BiP interacts with the large surface protein of hepatitis B virus in vitro and in vivo. J Virol. (2003) 77:2784-8. doi: 10.1128/JVI.77.4.2784-2788.2003

17. Lambert C, Prange R. Chaperone action in the posttranslational topological reorientation of the hepatitis $\mathrm{B}$ virus large envelope protein: implications for translocational regulation. Proc Natl Acad Sci U S A. (2003) 100:5199204. doi: 10.1073/pnas.0930813100

18. Garcia PD, Ou JH, Rutter WJ, Walter P. Targeting of the hepatitis B virus precore protein to the endoplasmic reticulum membrane: after signal peptide cleavage translocation can be aborted and the product released into the cytoplasm. J Cell Biol. (1988) 106:1093-104. doi: 10.1083/jcb.106. 4.1093

19. Wang J, Lee AS, Ou JH. Proteolytic conversion of hepatitis $\mathrm{B}$ virus $\mathrm{e}$ antigen precursor to end product occurs in a postendoplasmic reticulum compartment. J Virol. (1991) 65:50803. doi: 10.1128/JVI.65.9.5080-5083.1991
20. Xu Z, Jensen G, Yen TS. Activation of hepatitis B virus S promoter by the viral large surface protein via induction of stress in the endoplasmic reticulum. $J$ Virol. (1997) 71:7387-92. doi: 10.1128/JVI.71.10.7387-7392.1997

21. Hsieh YH, Su IJ, Wang HC, Chang WW, Lei HY, Lai MD, et al. Pre-S mutant surface antigens in chronic hepatitis B virus infection induce oxidative stress and DNA damage. Carcinogenesis. (2004) 25:202332. doi: $10.1093 /$ carcin/bgh207

22. Montalbano R, Honrath B, Wissniowski TT, Elxnat M, Roth S, Ocker M, et al. Exogenous hepatitis $\mathrm{B}$ virus envelope proteins induce endoplasmic reticulum stress: involvement of cannabinoid axis in liver cancer cells. Oncotarget. (2016) 7:20312-23. doi: 10.18632/oncotarget.7950

23. Huang Z-M, Tan T, Yoshida H, Mori K, Ma Y, Yen TSB. Activation of hepatitis B virus $S$ promoter by a cell type-restricted IRE1-dependent pathway induced by endoplasmic reticulum stress. Mol Cell Biol. (2005) 25:752233. doi: 10.1128/MCB.25.17.7522-7533.2005

24. Lazar C, Macovei A, Petrescu S, Branza-Nichita N. Activation of ERAD pathway by human hepatitis B virus modulates viral and subviral particle production. PLoS ONE. (2012) 7:e34169. doi: 10.1371/journal.pone.0034169

25. Li X, Pan E, Zhu J, Xu L, Chen X, Li J, et al. Cisplatin enhances hepatitis B virus replication and PGC-1 $\alpha$ expression through endoplasmic reticulum stress. Sci Rep. (2018) 8:3496. doi: 10.1038/s41598-018-21847-3

26. Ma Y, Yu J, Chan HL, Chen YC, Wang H, Chen Y, et al. Glucose-regulated protein 78 is an intracellular antiviral factor against hepatitis B virus. Mol Cell Proteom. (2009) 8:2582-94. doi: 10.1074/mcp.M900180-MCP200

27. Huang KL, Lai YK, Lin CC, Chang JM. Involvement of GRP78 in inhibition of HBV secretion by Boehmeria nivea extract in human HepG2 2.2.15 cells. J Viral Hepat. (2009) 16:367-75. doi: 10.1111/j.1365-2893.2009.01072.x

28. Shu W, Guo Z, Li L, Xiong Z, Wang Z, Yang Y, et al. Regulation of molecular chaperone GRP78 by HBV: control of viral replication and cell survival. $\mathrm{Mol}$ Cell Biol. (2019) 40:e00475-19. doi: 10.1128/MCB.00475-19

29. Wu L, Huang X, Kuang Y, Xing Z, Deng X, Luo Z. Thapsigargin induces apoptosis in adrenocortical carcinoma by activating endoplasmic reticulum stress and the JNK signaling pathway: an in vitro and in vivo study. Drug Des Devel Ther. (2019) 13:2787-98. doi: 10.2147/DDDT.S209947

30. Bouchard MJ, Wang LH, Schneider RJ. Calcium signaling by $\mathrm{HBx}$ protein in hepatitis B virus DNA replication. Science. (2001) 294:23768. doi: 10.1126/science.294.5550.2376

31. Zhu L, Jiang J, Zhai X, Baecker A, Peng H, Qian J, et al. Hepatitis B virus infection and risk of non-alcoholic fatty liver disease: a population-based cohort study. Liver Int. (2019) 39:70-80. doi: 10.1111/liv.13933

Conflict of Interest: The authors declare that the research was conducted in the absence of any commercial or financial relationships that could be construed as a potential conflict of interest.

Copyright (c) 2021 Chen, Mu, Liu, Hu, Tian, Zhang, Li, Yang and Lin. This is an open-access article distributed under the terms of the Creative Commons Attribution License (CC BY). The use, distribution or reproduction in other forums is permitted, provided the original author(s) and the copyright owner(s) are credited and that the original publication in this journal is cited, in accordance with accepted academic practice. No use, distribution or reproduction is permitted which does not comply with these terms. 